|| ISSN(online): 2589-8698 || ISSN(print): 2589-868X || International Journal of Medical and Biomedical Studies

Available Online atwww.ijmbs.info

PubMed (National Library of Medicine ID: 101738825)

Index Copernicus Value 2018: 75.71

Original Research Article

Volume 3, Issue 7; July: 2019; Page No. 123-127

\title{
SOCIO-DEMOGRAPHIC PROFILE OF THE PATIENTS WITH OCULAR TRAUMA
}

\section{Dr. Ashay Rameshwar Dangare ${ }^{1}$, Dr Amit Ashok Surana ${ }^{2}$}

${ }^{1}$ M.S. Ophthalmology, Assistant Professor, Dr PDMMC Medical College, Amrawati, Maharashtra

${ }^{2}$ Consultant Orthopedic and Spine surgeon, Sahyadri Hospitals, Vedanta Institute of Medical Sciences.

Article Info: Received 28 June2019; Accepted 19 July. 2019

DOI: https://doi.org/10.32553/ijmbs.v3i7.396

Address for Correspondence: Dr. Ashay Rameshwar Dangare, M.S. Ophthalmology, Assistant Professor, Dr PDMMC Medical College, Amrawati, Maharashtra

Conflict of interest: Nil

\section{Abstract}

Background: Ocular trauma is an important cause of preventable visual morbidity, particularly among younger age groups as shown by different studies worldwide. The impact of trauma on the human eyes may range from minute corneal abrasions/innocuous subconjunctival haemorrhage to a badly lacerated globe.

Aim: To study the Socio-demographical profile of the patients with ocular trauma

Methods: An observational study was carried out at the Department Of Ophthalmology, Burdwan Medical College and Hospital, a tertiary health care unit of West Bengal. The entire study was conducted after proper consultation and recommendations from the ethical committee. The research was carried out during a period of one year $(01 / 03 / 2010$ to 28/02/2011). A total of 120 patients were taken into consideration for the scope of the study.

Results: The patients were aged between 0-50 years were mostly suffered most ocular injuries. The research also showed that the majority of the affected patients were males, i.e. $75 \%$. Furthermore, in the course of the study, the majority of the patients belonged to the rural population, i.e. $71.5 \%$.

Conclusion: This study indicates that ocular trauma is a significant cause of monocular and sometimes binocular visual loss in all age groups. Many injuries and their visual outcome may be prevented through education and prompt, appropriate medical care.

\section{Introduction}

Ocular trauma is an important cause of preventable visual morbidity, particularly among younger age groups as shown by different studies worldwide ${ }^{1}$. The impact of trauma on the human eyes may range from minute corneal abrasions/innocuous subconjunctival haemorrhage to a badly lacerated globe. The spectrum of injuries ranges from mild, non-sight threatening to extremely serious with potentially blinding consequences. Though eyes represent only $0.15 \%$ of total body surface area, their importance to society and individual is much higher. ${ }^{2}$ Around the world, half a million blinding injuries occur every year. There are approximately 1.6 million people blind from eye injuries,2.3 million bilaterally visually impaired and 19 million with unilateral visual loss, this being the commonest cause of unilateral blindness today. ${ }^{3}$

OBT is the major cause of ocular trauma by the coup and contrecoup mechanism or by ocular compression. The concept of coup and contrecoup injury was first introduced to explain brain damage caused by blunt trauma to the head by Courville ${ }^{4}$.

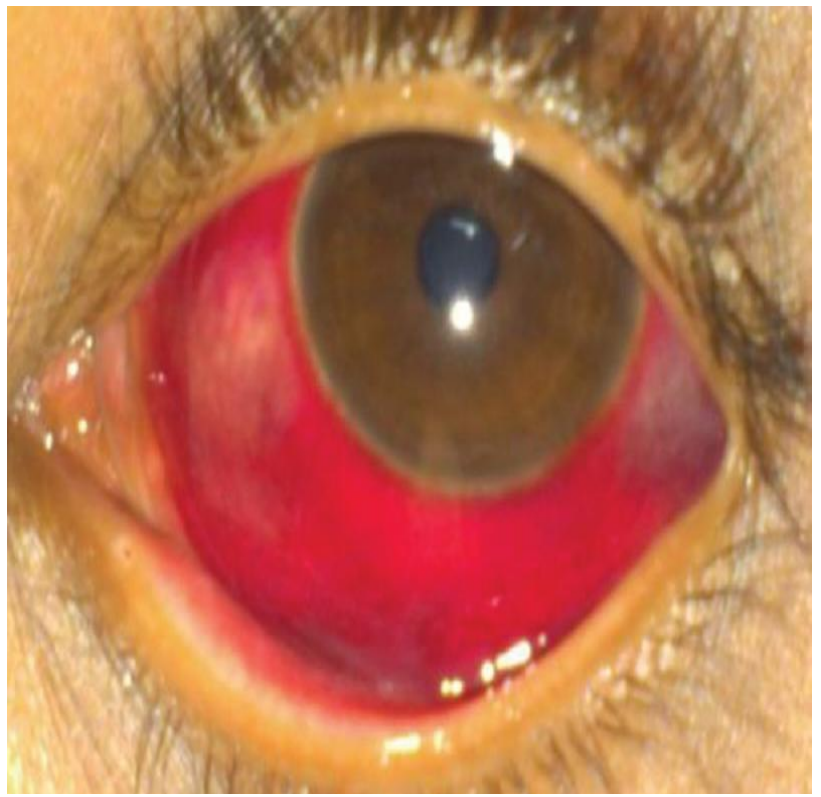

Figure 1: Subconjunctival hemorrhage ${ }^{5}$ 


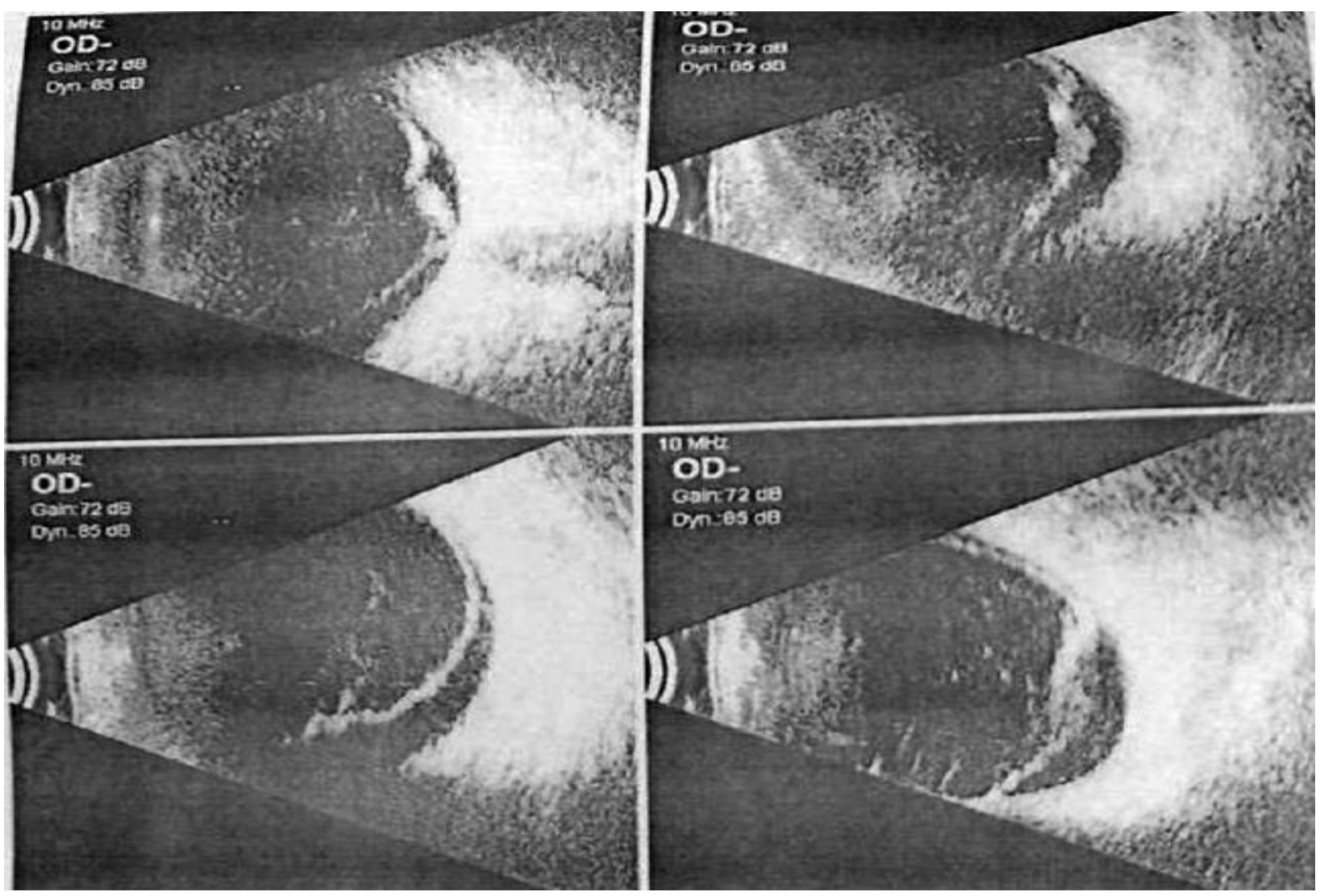

Figure 2: Ultrasonography B-scan showing retinal detachment ${ }^{6}$

Ocular trauma presents a significant number of new cases presenting to ophthalmic services to this part of India. Many of these are minor injuries and are treated either in accident and emergency departments or as outpatient cases. It has been noticed that the rural population is most affected by ocular injury ${ }^{7,8}$. In addition, it is sent that the males of younger age are the most affected by it. Ocular trauma has been identified as an important cause of blindness and ocular morbidity. The major cause of death due to ocular trauma is illiteracy ${ }^{9}$.

\section{Aim}

To analyze the socio-demographical profile of the patients with ocular trauma requiring tertiary care.

\section{Methods}

An observational study was carried out at the Department Of Ophthalmology, Burdwan Medical College and Hospital, a tertiary health care unit of West Bengal. The entire study was conducted after proper consultation and recommendations from the ethical committee. The research was carried out during a period of one year (01/03/2010 to 28/02/2011). A total of 120 patients were taken into consideration for the scope of the study. Along with the demographic data, the complete history of the mishap and other details of the details of the injury through which ocular trauma had occurred. Complete details of ophthalmic examination including initial best-corrected visual acuity, lid or facial injury, any pupillary defect, presence or absence of a foreign body, and corneal or scleral or corneoscleral perforation were noted. The presence or absence of vitreous haemorrhage, retinal breaks, retinal detachment and choroidal rupture, was noted. Direct ophthalmoscopy, indirect ophthalmoscopy, slit lamp examination, and ocular B-scan ultrasonography was used to examine the anterior and posterior segments and the orbits. Intraocular pressure was measured in all except in fresh open globe injuries.

\section{Results}


Table 1:

\begin{tabular}{|c|c|c|}
\hline & No of cases & Percentage (\%) \\
\hline \multicolumn{3}{|l|}{ Mechanism of ocular injury } \\
\hline Mechanical & 111 & 92.5 \\
\hline Chemical/Thermal/Electrical/Fire Cracker Injury & 9 & 7.5 \\
\hline \multicolumn{3}{|l|}{ Age group } \\
\hline $0-10$ & 27 & 22.5 \\
\hline $11-20$ & 26 & 21.67 \\
\hline $21-30$ & 18 & 15 \\
\hline $31-40$ & 12 & 10 \\
\hline $41-50$ & 14 & 11.66 \\
\hline $51-60$ & 8 & 6.66 \\
\hline $61-70$ & 6 & 5 \\
\hline $71-80$ & 9 & 7.5 \\
\hline \multicolumn{3}{|l|}{ Sex } \\
\hline Male & 91 & $75.83 \%$ \\
\hline Female & 29 & $24.17 \%$ \\
\hline \multicolumn{3}{|l|}{ Residence } \\
\hline Urban & 34 & 28.33 \\
\hline Rural & 86 & 71.67 \\
\hline \multicolumn{3}{|l|}{ Education Status } \\
\hline Illiterate & 50 & 41.67 \\
\hline LNFE & 16 & 13.34 \\
\hline Primary & 28 & 23.33 \\
\hline Higher secondary & 26 & 21.66 \\
\hline \multicolumn{3}{|l|}{ Occupation } \\
\hline Carpenter & 2 & 1.67 \\
\hline Shop owner & 2 & 1.66 \\
\hline Farmer & 13 & 10.83 \\
\hline Factory worker & 6 & 5 \\
\hline Housewife & 20 & 16.67 \\
\hline Laborer & 27 & 22.5 \\
\hline Student & 29 & 24.16 \\
\hline Others & 21 & 17.5 \\
\hline \multicolumn{3}{|l|}{ Socio-Economic Status } \\
\hline Lower & 39 & 32.5 \\
\hline Upper lower & 26 & 21.67 \\
\hline Lower middle & 36 & 30 \\
\hline Upper middle & 17 & 14.16 \\
\hline Upper & 2 & 1.67 \\
\hline \multicolumn{3}{|l|}{ Addiction of the patients } \\
\hline No & 79 & 65.83 \\
\hline Smoking & 22 & 18.34 \\
\hline Smoking +drinking & 17 & 14.16 \\
\hline Tobacco chewing & 2 & 1.67 \\
\hline
\end{tabular}


In this study, the total numbers of patients were 120. Out of which $92.5 \%$ (111) have mechanical injuries, and $7.5 \% \quad$ (09) patients have Chemical/Thermal/Electrical/Fire Cracker injuries. Most ocular injuries (80.83\%) occurred within the age group 0-50. Study shows the incidence of ocular injuries between age group 70-80 was $7.5 \%$. Further, 91 patients (75.83\%) were male, and $29(24.17 \%)$ were female. As shown in the table, 34 (28.33\%) patients reside in an urban area, while $86(71.67 \%)$ patients reside in a rural area. Among 120 patients, 50 patients $(41.67 \%)$ were illiterate, while 70 patients (58.33\%) were literate. Among the injured patients, the common occupations were students (24.16\%), labourers $(22.75 \%)$, housewives $(16.67 \%)$ and farmers (10.83\%). Others constitute significant number 21 (17.5\%) of patients. The above table shows the distribution of patients on the basis of socioeconomic status according to Dr.B.G.Prasad's scale. Maximum patients $39(32.5 \%)$ are from the lower class, 26 $(21.67 \%)$ patients are from upper lower while 36 (30\%) patients are from the lower middle class. The upper middle class consists of 17 (14.16\%) patients, while upper class consists of just $2(1.67 \%)$ patients. Surprisingly in this study, the majority (65.85\%) of patients having ocular trauma have no addiction; while $41(34.13 \%)$ patients have some addiction.

\section{Discussion}

Epidemiological studies of ocular trauma are done in several ways. The first is a hospital-based study of ocular injuries over specific time period ${ }^{10}$. The second way is a voluntary registry, such as Eye Injury Registry of Albama ${ }^{11}$ and The National Eye Trauma System ${ }^{12}$ and third is measuring the incidence of eye injuries in a defined population ${ }^{13}$. In the present study, the incidence of injuries is quite high among the illiterate, young and rural population. The number of patients between age groups $0-10 y r s$ $(22.5 \%)$ is most commonly affected closely followed by age group $10-20$ yrs (21.67\%). This is really a very high percentage in the group of ocular injuries, which most frequently caused permanent disability; predetermining further life destiny of these young people. Takvan J V et al ${ }^{14}$ reported that the incidence of pediatric age group trauma is up to $14 \%$. According to Sriwas $S R^{15}$, the incidence of child trauma is $22 \%$, which is approximately equal to present study findings. Voon LW et $\mathrm{al}^{16}$ found that most of the ocular injuries are male and below 40 years. In the present study population, males are predominantly affected. Males were $75.0 \%$, and females are $25 \%$. Soliman MM et $\mathrm{al}^{17}$ observed that $80 \%$ of cases are males. Jovanovic Milos et al ${ }^{18}$ stated that males are predominantly affected (83.56\%). Further, 86 (71.67\%) patients are rural, while 34 (28.33\%) patients are urban. As Burdwan Medical College and Hospital is the main hospital in the surrounding area of Burdwan, Birbhum, Hoogly, Parganas and some area of Jharkhand ( which is the mainly rural area); the number of patients belonging to the rural area is higher. McCarty Cathy A et $\mathrm{al}^{19}$, in a similar study in Australia, found that the incidence of ocular trauma is $42.1 \%$.

In the present study, $92.5 \%$ of patients had mechanical injuries and rest $7.5 \%$ had chemical/thermal/firecracker injury. A study conducted in Split-Dalmatian County by Karaman et $\mathrm{al}^{20}$ showed the incidence of mechanical injury and chemical/thermal injury are $86.4 \%$ and $13.6 \%$ respectively. In the present study, the incidence of mechanical injuries is slightly higher. Further, in the present study, $41.67 \%$ of patients were illiterate while $13.34 \%$ of patients were literate but having no formal education. Moreover, $23.33 \%$ of patients had primary education, while $21.66 \%$ of patients had higher secondary and further education. Specifically, in females, the rate of literacy was quite low (17.43\%). This finding is not by chance as the majority of patients in the hospital were from rural areas. In the present study, the incidence of injuries is quite high among the illiterate and rural population. S Vats et $\mathrm{al}^{21}$ also shared similar findings. Singh $\mathrm{D} \mathrm{V}$ and other investigators ${ }^{22}$ came at a similar conclusion in their study. In almost all models of studies, literacy offered significant protection against trauma. According to Glynn et al $^{23,}$ poor and less educated persons are more prone to risk-taking activities and thus to be injured. In their study, Karaman et $\mathrm{al}^{20}$ found that farming is responsible for $13.8 \%$ of injuries, which is similar to the present finding. Finally, in the present study, the majority (65.83\%) patients had no addiction. Smoking was the addiction for $18.34 \%$ of the patients, followed by combined smoking and drinking (14.16\%). Wang $J \mathrm{D}^{24}$ in Beijing found drinking alcohol as one of the most important risk factors associated with ocular trauma. Reporting 
bias by the patients might be responsible for the present findings.

\section{Conclusion}

This study indicates that ocular trauma is a significant cause of monocular and sometimes binocular visual loss in all age groups. Many injuries and their visual outcome may be prevented through education and prompt, appropriate medical care. The goal of data collection is to identify trends on the basis of which primary, secondary and tertiary prevention may be developed. For the prevention of serious eye injuries, health education and safety strategies should be applied both at home and the place of work, where blinding injuries most frequently occur. Open globe injuries in a rural environment are still a big therapeutic, social and economic problem. Occupational open globe injuries are usually severe and are associated with poor visual outcome. Mandatory use of protective eyewear and alcoholfree environment at the workplace is likely to reduce the incidence of severe occupational globe injuries.

\section{References}

1. Parmar NRC, Sunandan S. Pattern of ocular injuries in Haryana. Ind J Ophthalmol 1985;33: 141-144.

2. Nordber E. Injuries as a public health problem insubSaharan Africa: Epidemiology and prospects for control. East Afr Med J. 2000;77:1-43.

3. Negrel AD, Thylefors B. The global impact of eye injuries. Ophthalmic Epidemiol 1998; 5:143-169.

4. Courville CB. Coup-contre coup mechanism of craniocerebral injuries. Arch Surg 1942;45:9.

5. Maiya A.S. Dharmesh A.M. Jayram R. Clinical profile of ocular blunt trauma in a rural hospital. J Clin Opthal \& Res. 2018; 6(1):3-7.

6. Steiner G, Peterson L. Severe emotional response to eye trauma in a child: awareness and intervention. Arch Ophthalmol 1992;110:753

7. Michael $\mathrm{I}$, Moses $\mathrm{CH}$, Michael $\mathrm{B}$. Ocular injuries in Malawi. Br J Ophthalmol 1982;66:145-148.

8. Umeh RE, Umeh OC. Causes and visual outcome of childhood eye injuries in Nigeria. Eye 1997;11:489495
9. Ilsar $M$, Chirambo $M$, Belkin $M$. Ocular injuries in Malawi. Br J Ophthalmol 1982;66:145-148.

10. Wykes WN: A 10 year survey of penetrating eye injuries in Gwent. Br J Ophthalmol 1987;72:606-11

11. Morris RE et al. Eye injury registry of Albama demographics and prognosis of severe eye injury. South med J 1987;810-16

12. Parver LM: Eye trauma: The neglected disorder. Arch Ophthalmol 1986;104:1452-53

13. Kerlson TA, Klein B. The incidence of acute hospital treated eye injuries. Arch Ophthalmol 1986;104:147376.

14. Takvam JV, Midelfort A. Survey of eye injuries in Norwegian children. Acta Ophthalmol 1993;71:500-5.

15. SR Shriwas, Aung $Z$ Kinzha. Orbital injuries in children : Play-related. Indian J Ophthalmol 1993;41:129-30

16. Voon LW. Sec J. Wong TY. The epidemiology of ocular trauma in Singapore. Eye 2001;15:75-81

17. Soliman MM, Macky TA. Pattern of ocular trauma in Egypt. 2008;246:205-12.

18. Jovanović M, Stefanović I. Mechanical injuries of the eye: incidence, structure and possibilities for prevention. VOJNOSANITETSKI PREGLED 1930;67: 12

19. McCarty CA, Cara L.H Fu, Taylor HR. Epidemiology of ocular trauma in Australia. Ophthalmology 1999;106:1847-52

20. Karman K, Antunica AG, Perk SR. Epidemiology of adult eye injuries in Split- Dalmatian County. Croatian Medical Journal 2004;45:304-309

21. Vats S, Murthy GV, Chandra M, Gupta SK, Vashist P, Gogoi M. Epidemiological study of ocular trauma in an urban slum population in Delhi, India. Indian J Ophthalmol. 2008;56:313-6.

22. Singh DV, Sharma YR, Azad RV, Talwar D,Rajpal. Profile of Ocular Trauma at Tertiary Eye Centre. JK SCIENCE 2005;7: 1.

23. Glynn RJ. Seddon JM, Berlin BM. The incidence of eye injury in new England adults. Arch Ophthalmol 1988;106:785-89.

24. Wang JD, Xu L, Wang $Y$, You $X$, Zhang QS, Jonas JS. Prevalence and incidence of ocular trauma in North China: the Beijing Eye Study. Acta Ophthalmologica 2011. 